\title{
Reproduction as Literary Production: Self-Expression and the Index in Kenneth Goldsmith's Uncreative Writing
}

\author{
Ioannis Tsitsovits
}

\section{INTRODUCTION}

How big a liability is self-expression for contemporary writing? Through what kinds of techniques could one attempt to stifle it? Viewed from a certain angle, the work of Kenneth Goldsmith confronts writing instruction with some thought-provoking questions. For the better part of his career, the self-proclaimed conceptual writer has mounted a sustained effort to countervail the emphasis on creativity, authenticity, and a personal voice that he considers the defining trait of today's literary world. The evidence of this antagonism is manifold. To start with, there is Goldsmith's output itself: most emblematically, his 840-page tome Day (2003), a word-for-word retyping of the September 1, 2000 issue of the New York Times (including advertising copy), or his "New York trilogy," a book series made up of radio broadcast transcripts. ${ }^{1}$ There is the titular antipathy of Against Expression (2011), an anthology of conceptual

I. Tsitsovits $(\bowtie)$

KU Leuven, Leuven, Belgium

(C) The Author(s) 2021

291

A. Masschelein and D. de Geest (eds.), Writing Manuals

for the Masses, New Directions in Book History,

https://doi.org/10.1007/978-3-030-53614-5_12 
writing which, his co-editor Craig Dworkin claims, avoids "familiar strategies of authorial control in favor of automatism, reticence, obliquity, and modes of noninterference" (Dworkin 2011, pp. xliii-xliv). Finally, there is Uncreative Writing (2011), a publication that is equal parts primer, manifesto, and literary advice. Probably Goldsmith's most explicitly pedagogical text, the book includes a reckoning with the Uncreative Writing course he has been teaching at the University of Pennsylvania, alongside insights on the authors he regards as his conceptual peers and predecessors. As such, it proffers both a rationale for his own modus operandi and certain answers to the questions which began this paragraph.

From its opening pages, in fact, it becomes clear that the overarching argument in Uncreative Writing is underpinned by a McLuhanesque logic of media determinism. Among the most profound ramifications ushered in by digital technology and the worldwide web, Goldsmith notes, is the sheer excess of the written word: "faced with an unprecedented amount of available text, the problem is not needing to write more of it; instead, we must learn to negotiate the vast quantity that exists" (Goldsmith 2011, p. 1). Literature, he says, has reached a crossroads similar to that encountered by painting after the advent of photography. In the wake of the myriad possibilities for textual manipulation that have emerged in the last decades, the trappings of traditional literariness-among them selfexpression, lyricism, immersive narrative, and plot-hold less importance than one's ability to manage and disseminate information. Correspondingly, we have witnessed "an explosion of writers employing strategies of copying and appropriation over the past few years, with the computer encouraging writers to mimic its workings" (ibid., p. 5). Part of the purpose of Against Expression and Uncreative Writing is to give pedagogically accessible contours to this explosion, while also laying claim to its genealogical precursors. Indeed, next to writings by Gertrude Stein and Andy Warhol, these books showcase and contextualize an often digitally enabled gamut of textual collage, appropriation, and constraint-based practices, such as those found in the projects of Tan Lin, Vanessa Place, and Thomas Claburn. Despite such work, however, Goldsmith insists that today's literature is largely shutting itself off from a wider cultural milieu that is "embracing the digital and all the complexity it entails" (ibid., p. 7). Instead of drawing on these recent technological innovations to renew itself, he says, literature remains "mostly wedded to promoting an authentic and stable identity at all costs" (ibid.). 
Crucially, Goldsmith singles out creative writing pedagogy as a potential culprit for this lag. Writing handbooks come under especially acerbic scrutiny: "In regard to the many sophisticated ideas concerning media, identity, and sampling developed over the past century," he ventures, "books about how to be a creative writer have completely missed the boat, relying on clichéd notions of what it means to be "creative"" (ibid.). Goldsmith's indictment resonates with recent essays that criticize the literary advice industry on fairly similar grounds. Stretching from the late nineteenth century to the early twenty-first, Michelene Wandor's survey of writing handbooks, for instance, highlights their bias toward exercises "drawing on personal, real-life experiences," a habit which "over-privileges the personal and fetish[iz] es the autobiographical" (Wandor 2008, p. 110). Nancy Kuhl has likewise warned of the counterproductive promotion of "writing-as-self-exploration," exemplified by books such as Julia Cameron's 1992 bestseller The Artist's Way (Kuhl 2005, p. 7). For Kuhl, such guides are symptomatic of a pervasive and ultimately deleterious confusion of writing with soul searching and psychotherapy, especially in North American popular culture. Even Alexandria Peary's more sympathetic take on "the informal aesthetic education of writers," as she calls it, effectively treats writing handbooks as subsidiary to the self-help industry, with their implied diktat "Go inward, writer" being a call for "self-engagement" (see Peary in this volume). One attribute of literary advice that all these studies point to, whether approvingly or critically, is its tendency to present writing as a route to self-discovery and personal development.

However, while these criticisms and those leveled by Goldsmith lock onto the same target, they are respectively launched from quite different positions. Unlike the academic texts mentioned above, Uncreative Writing is a book providing literary advice in its own right. In this sense, it performs what is here taken as the genre's principal function, which is to advocate models of literary production. More specifically, the model Goldsmith espouses in Uncreative Writing is introduced as an aesthetic antidote of sorts; it is a model that implies the ideological infiltration or correction of a literary field in which, as Wandor puts it, "the quest is for the writer beneath the work, not the work itself" (Wandor 2008, p. 111). This allows Goldsmith to present his countermodel as a much-needed alternative or remedy which, in the context of his technologically inflected argument, stakes a claim for its contemporary 
relevance. Furthermore, several critics have aligned themselves with Goldsmith's self-appraisal. Marjorie Perloff, for example, echoes him when she argues that his work is premised on the malleability of language "in a digital environment" (Perloff 2010, p. 164), while Jeffrey Nealon sees his conceptualism both as a rejection of "affective capitalism" and as a kind of 2.0 version of postmodern anti-interpretive critiques (Nealon 2017, p. 78$)$.

Taking a somewhat different approach, this article examines Uncreative Writing's pedagogy in connection to a history of indexical artistic practices and of copying as a form of literary advice. As I argue below, Goldsmith's writing exercises can best be understood as the deployment of a principle of indexicality through which Rosalind Krauss read the emergent art of the 1970s, and which according to her thesis underlies not only analog photography, but Duchamp's readymades and the grammatical category of the shifter. In this sense, Goldsmith's advice expands a proto-photographic logic into the territory of contemporary literature. I explain, moreover, how the practice of copying at the heart of his project is, in fact, part of traditional self-expressive literary advice. I illustrate that point by way of R. V. Cassill's Writing Fiction (1962), contending that the writing exercises in Uncreative Writing are no less "wedded to promoting an authentic and stable identity" than Cassill's pedagogical approach. Whereas in Cassill this promotion is linked to the assimilation of copying into an imitative process, in Goldsmith it follows an indexical and therefore less evidently self-expressive logic. In the final section of the article, I consider what kind of subjectivity might be expressed through Goldsmith's model, concluding with an brief assessment of the role of Uncreative Writing in terms of both its educational and polemic functions.

\section{EXERCISES IN UNCREATIVITY}

Uncreative Writing borrows its title from the class that Goldsmith has been teaching for over fifteen years at the University of Pennsylvania. "In it," he explains, "students are penalized for showing any shred of originality and creativity" (Goldsmith 2011, p. 8). In the chapter that offers an account of his educational practices, Goldsmith lists the following five writing exercises as part of his pedagogical approach: "Retyping Five Pages," "Transcribing a Short Piece of Audio," "Transcribing Project Runway," "Retro Graffiti," and "Screenplays." With the exception of 
"Screenplays," which involves scripting pedantically precise screenplays for films or video clips, none of these exercises require any linguistic input from his students (or readers) for their completion and would actually seem to discourage such initiatives. "Retro Graffiti," for instance, simply entails the public display (or insinuation into public space) of "arcane texts or out-of-date slogans," while "Transcribing Project Runway" is the product of his students' simultaneous transcription, over Internet chat, of an episode of the reality TV series Project Runway (ibid., p. 210). As a first observation, then, we could say that these tasks broadly signal a refusal to produce new verbal content. In keeping with Goldsmith's practice and conceptual writing as a whole, literary production is reduced to a series of activities for repurposing, recording, or reframing language.

As Goldsmith's exercises show, his writing model is not necessarily tied to the use of state-of-the-art technology: "Retyping Five Pages," "Retro Graffiti," and "Transcribing a Short Piece of Audio" could easily dispense with the internet or a laptop altogether. Several critics have, in fact, addressed the apparent incongruity of Goldsmith's touting of the contemporary vitality of his work when, from a technical point of view, his project is comparatively old-fashioned. David Kaufmann, for example, remarks that while the Internet might have made Goldsmith's output easier, not one of his books "depends for its actual existence on the Web" (Kaufmann 2017, p. 19). The exercises listed in Uncreative Writing nonetheless suggest that conceptual writing, at least as Goldsmith understands and practices it, rests on a formal rather than technological disposition. Paul Stephens has characterized the strategies used in conceptual writing as "passive indexing" (Stephens 2015, p. 154). As he argues, such literary practices suggest an interest in "the bureaucratic forms taken by large quantities of information," frequently producing works that "thematize in some manner the relation of a writer to a data set"-hence the "parodic compendia" that are exemplary of the genre (ibid.). Although, as we will see, the index is a helpful concept for approaching Goldsmith's work, Stephens's terms tend to circumscribe it within the area of information systems and Big Data. With the exception of "Transcribing Project Runway," the logic of the database is not necessarily an accurate blueprint for the repertoire of writing exercises in Uncreative Writing.

Craig Dworkin has used the term "interface" to describe conceptual writing's formal disposition, which often operates, as he puts it, by "returning the answer to a particular query; assembling, rearranging, and displaying information; or sorting and selecting from files of accumulated 
language pursuant to a certain algorithm - rather than producing new material from scratch" (Dworkin 2011, p. xlii). He consequently argues that "[e]ven if it does not involve electronics or computers, conceptual poetry is thus very much a part of its technological and cultural moment" (ibid.). Framing the practice in this way is, on the one hand, a means of pre-empting criticisms such as Kaufmann's. On the other hand, Dworkin's definition casts its net wider than it may seem. Thinking of "algorithm" simply as a formula for ordering the appropriation of words from existing verbal matter opens the door to a chronologically flexible conception of conceptual writing. His comments consequently can also be read as a legitimation of the protracted genealogy of the genre, which in Against Expression and Uncreative Writing extends back well beyond the information age. This elasticity enables Goldsmith to position his own work within a pliant lineage that not only includes the writings of Duchamp and Andy Warhol but those of Jacques Diderot and Stéphane Mallarmé, and therefore to participate in his own canonization.

Yet what if we also approached Stephens's notion of indexing with a broader chronology in mind? A pivotal reference point for Against Expression and Uncreative Writing is the conceptual art of the late 1960s and 1970s: Sol LeWitt's wall drawings and writings in particular come into special prominence in Goldsmith's book. As Stephens acknowledges, these art practices set an important precedent for the indexical logic he is attempting to map out. However, his analysis leaves out a milestone in the theorization of this logic as it manifests itself in that art, namely Rosalind Krauss's 1977 essay "Notes on the Index." One merit of Krauss's extraordinary text is that it offers a theoretically rigorous understanding of the index that does not limit itself to a narrow chronological period. So although she sets out to explain the principles uniting the apparent heterogeneity of the new art of the time, her art-historical departure point is the oeuvre of Duchamp, in which she sees a protophotographic quality. What the photograph and Duchamp's work have in common with the 1970s art in her purview, she argues, is their adherence to the logic of the index. Indexes - a semiotic category which, she says, includes footprints, medical symptoms, and cast shadows- "are the marks or traces of a particular cause, and that cause is the thing to which they refer" (Krauss 1977, p. 70). ${ }^{2}$ The reason both the photograph and the readymade are indexical, according to Krauss, has to do with their mode of production: "It is about the physical transposition of an object from 
the continuum of reality into the fixed condition of the art-image by a moment of isolation, or selection" (ibid., p. 78).

\section{The Logic OF THe INDEX}

With some reworking, an equivalent statement could be made about Goldsmith's model of literary production. It is a model, we could say, that involves the transposition of a slice of verbal matter from the vast quantity surrounding us into the fixed condition of a textual object by a moment of isolation, or selection. Of course, while analog photography is typically considered an exemplary indexical medium, the suggestion that writing might function as an index-other than in the obvious sense of its indexical relation to the means (the pen, keystrokes, printer, etc.) by which it was inscribed-might appear somewhat odd. ${ }^{3}$ It is worth noting, however, that the concept of the shifter through which Krauss launches her analysis is not borrowed from art history or photography, but from linguistics. ${ }^{4}$ Shifters, she writes, include pronouns and demonstratives such as "this"-words which despite being "part of the symbolic code of language" are indexes because "their meaning depends on the existential presence of a given speaker" (ibid., p. 70). Like the readymade and the photograph, the shifter is therefore "a sign which is inherently "empty," a "meaningless meaning that is instituted through the terms of the index" (ibid., p. 78). As Mary Ann Doane observes in her 2007 reading of Krauss's essay, this argument entails "no tension between the index as [material] trace and the deictic index; both involve the sheer affirmation of an existence" (Doane 2007, p. 3). ${ }^{5}$

This understanding of the index, it seems to me, provides a useful way of grasping Goldsmith's writing pedagogy that moves beyond the notion of a passive indexing tied to "the forms taken by the bureaucratic mechanisms of contemporary capitalism" (Stephens), or an interface eschewing the production of "new material from scratch" (Dworkin). Consider, for instance, the "Screenplays" exercise, which technically speaking does implicate the creation of new writing from scratch. "Take a film or video that has no screenplay," Goldsmith instructs, "and make one for it, so precisely notated that it could be recreated after the fact by actors or nonactors" (Goldsmith 2011, p. 211). In addition, its format "should have nothing left to chance or whim about it," but instead should "adhere to the preordained formatting constraints that are the screenwriting industry standards" (ibid.). As a recipe for text-making, the 
exercise aspires to a logic that is fundamentally indexical: it aspires, that is, to a condition in which the writing merely registers the presence of an object, which in this instance happens to be visual rather than verbal. The apparent purpose of the task's prescriptive pedantry is to reduce its outcome to a deictic affirmation of the film or video's existence. In this way, "Screenplays" is kept in line with the character of the other assignments.

What Krauss in her analysis refers to as the "meaningless meaning" of the shifter and the photograph also sheds further light on Goldsmith's practice. For instance, in the case of Day, his newspaper retyping project, Krauss's oxymoron can be understood in terms of the subordination of the New York Times's descriptive, propositional content-what, borrowing from speech act theory, we would call its constative component-to the performance of its textual reproduction. As Doane also remarks about the indexical artworks Krauss examines in her essay: "[they] simply register their world, taking on the form of performative evidence rather than constative statement" (Doane 2007, pp. 3-4). A similar claim could be made about Goldsmith's writing exercises. "Retro Graffiti" is an obvious concretization of this principle. In most responses to the exercise, the meaning of the appropriated phrases was subsumed under the task's performative character: one student, for example, memorably inscribed part of Virginia Woolf's A Room of One's Own (1929) in tiny letters on the skin of a banana and placed it in a fruit bowl. Yet even in the case of a less obviously stunt-like exercise such as "Retyping Five Pages" the overall effect is the demotion of the text's signification, its consignment to the status of performative evidence. It is quite telling that, as Goldsmith writes, classroom discussions of the "Retyping Five Pages" exercise revolve around its deictic affirmation of another text ("the choice of what to retype"), its performative function (some students "find the task unbearable"; "others discover that it is relaxing and Zen-like"; one student "says she finds the exercise closer to dancing than to writing"), or the form this function takes, including the various "paratextual devices" through which the assignment is embodied or presented (Goldsmith 2011, pp. 202-203). The task, in other words, is both structured and framed as an indexical operation.

There are several reasons why the indexicality Goldsmith espouses might be of interest to an anti-expressive program. For one, his writing protocols could be considered anti-expressive in the broader sense of their restrictive impact on an author's compositional input. In addition, 
because it posits writing as a means of copying, recording, or transcribing pre-existing material, Goldsmith's model short-circuits the prerequisite of an originary voice that frequently sustains the ideal of self-expression. Another factor, related to the previous ones, is the indexical demotion of the constative: adhering primarily to a deictic rather than propositional or descriptive principle, Goldsmith's writing assignments seem ill-suited to an exploration of an author's thoughts or psychological states. Despite the putative anti-expressive effects of such restrictions, however, recalling the performative bias of these tasks should be enough to make one realize that curbing self-expression is not an easy or straightforward project.

It is interesting, in that regard, to consider the kind of writing that is generated when it relies on looser indexical parameters than those of Goldsmith's exercises. One example is his Capital (2015), a text made up entirely of quotes from books on New York City. It is revealing that a work Goldsmith describes in fairly expressive terms-its "function," he explains, is "to give a completely poetic and subjective view of the way one person might find his way through the mass of literature written about the capital of the twentieth century, New York" (cited in Perloff 2010, p. 168)—should also conform to a less rigorous indexicality. Modeled on Walter Benjamin's unfinished Arcades Project (1927-1940), Capital is the product of a permutational arrangement that allows us to speak of its composition in a way that would not be as plausible for Day, or for the exercises featured in Uncreative Writing.

And yet, as Jennifer Ashton has recently remarked, Goldsmith's suggestion of Capital's expressive function "is simply to make explicit a logic that has been implicit all along" (Ashton 2018, p. 227). This logic turns around the notion of the author's choices, both in the selection of the cited or appropriated text and the implied or stated rules by which a writer reproduces it. Such choices, moreover, cannot help but register the author's personal predilections. In other words, not only is it possible for a work like Capital to be self-expressive, it is impossible for Goldsmith's writing model as a whole not to be self-expressive. Reflecting on the "Transcribe a Short Piece of Audio" assignment, for example, Goldsmith writes: "How we hear - and how, in turn, we process that hearing into written language - is riddled with subjectivity. What you hear as a brief pause and transcribe as a comma, I hear as the end of a sentence and transcribe as a period" (Goldsmith 2011, p. 205). Similar 
observations can be made about the other writing exercises. ${ }^{6}$ As Goldsmith freely acknowledges in his book's introduction, "the suppression of self-expression is impossible" (ibid., p. 9).

The entire rationale of the indexical curtailment of authorial expression thus inevitably inverts and ends up homing in on the persona of the author. This reversal is also thrown into relief by the realization that, by valorizing writing as performative evidence, indexicality actually fosters self-expression-something that Goldsmith's exercises make abundantly clear. Yet where does this leave Goldsmith's antagonism to the kind of literary advice that advocates "a stable and authentic identity"? I will be returning to this question in what follows. Before doing so, however, it is worth noting that the primary vehicle through which Goldsmith endeavors to set his model apart from such advice (i.e., the use of textual reproduction as a writing process) is also integrated in explicitly selfexpressive "how-to" guides. How, then, would a traditional self-expressive writing handbook rationalize the inclusion of copying in its repertoire of exercises? And what might this tell us about Goldsmith's own endeavor?

\section{Self-Expression via Copying Vs. Copying as SeLf-Expression}

On the face of it, R. V. Cassill's Writing Fiction is one of those "terribly unsophisticated" "how-to" books that are dismissed in Uncreative Writing (ibid., p. 8). In an early chapter titled "Choosing a Subject" Cassill warns of the temptation "to turn from concentration on our own experience to the public world of great events - to write about spies and congressmen" (Cassill 1962, p. 23). Instead, "the first commandment is to go back stubbornly to our own fields. This time - and the next time and the time after that - we must turn them more deeply than before" (ibid.). This commitment to harnessing the personal is then collapsed into the following plea: "In the long run the reward for this may only be that the writer will discover who he really is" (ibid.). Reading like a paean to self-expression, Cassill's passage takes as its starting point a shopworn principle of literary advice (the equivalent of "write what you know"), only to put it in the service of an imperative to explore and find one's genuine self. It should be added that his pedagogical approach is firmly rooted in classroom instruction: in the first sentence of the book, Cassill announces that it is "the summary of what I have said in the last twelve years to my classes in fiction writing" (ibid., p. xi). What is more, 
during 1948-1952 and 1960-1966 Cassill taught at The Iowa Writers' Workshop (Sage 1974, p. 262). Readers acquainted with the Workshop's history will already know that this background carries a considerable institutional weight. Even in the diversifying realm of today's creative writing programs, the name of the Iowa Workshop- "the most influential linking of an educational institution with literary production ever" (McGurl 2007, p. 527)—remains associated with a writing model that is paradigmatically self-expressive. ${ }^{7}$

To all appearances, then, it would be hard to reconcile Cassill's advice with that offered in Uncreative Writing. Besides the shared fact of their origins in classroom teaching, the two books seem to have precious little in common. Nevertheless, Cassill's traditional and fully institutionalized "how-to" guide also embraces textual reproduction as part of its regime of writing exercises. Although he favors emulation over "mechanical borrowing or stealing" and warns his readers that "[w]riting is not just typewriting" (Cassill 1962, p. 3)-a claim in direct conflict with a work like Goldsmith's Day-Cassill recognizes the literary benefits of "outright copying or imitation" (ibid., p. 6). In a subsequent section, he recommends that readers reproduce the last two pages of a story printed in its entirety in Writing Fiction. This act of textual cloning is merely offered as a "finger exercise," a means to another end rather than proper literary work. In principle, however, Cassill's copying task is identical to the "Retyping Five Pages" assignment in Uncreative Writing. From this perspective, it is tempting to regard the process of producing Day as an oversized rendition of what has for some time now been a simple and uncontroversial piece of literary advice.

Even more surprising, however, given his earlier self-expressive imperative, is Cassill's theoretical justification of the copying exercise, which posits literary production as inherently derivative:

If I have begun by advocating some rather dry and mechanical forms of imitation, let me conclude by saying that imitation shades very gradually into all works that we properly think of as original. There cannot be, and probably there should never be, any piece of fiction that does not derive from other literary works, though the connections between one piece and whatever served as a model may be infinitely subtle and varied. (ibid., p. 56) 
Were we to isolate the first part of his second sentence, replacing "fiction" with "conceptual writing," and "literary works" with "verbal matter," we would essentially extract a recipe for Goldsmith's practice. All the same, Cassill's conception of original literature as the offshoot of mimetic processes-a proposition going at least as far back as Voltaire's pronouncement that "originality is nothing but judicious imitation" (1786, p. 410)-suggests a very different take on the utility of textual reproduction. Cassill treats copying as a stepping stone, something that ultimately paves the way to self-expressive writing. For Goldsmith, in contrast, copying is the writing: from the point of view of pedagogy, this is all an aspiring writer needs to learn in order to start working. The rift between these methodologies becomes obvious when considering the fact that Cassill also instructs his readers to perform the copying exercise without keeping their eyes on the source text. They are encouraged, instead, to test their memory for the composition of sentences and paragraphs, and to hone their "sensitivity to style" so as to utilize their "memory of language and its resources in various combinations" (Cassill 1962, pp. 55-56). In Writing Fiction copying is not performed for its own sake, as it is in Uncreative Writing; rather, textual reproduction evolves into the imitative assimilation of other writers' styles.

From the point of view of Cassill's book, then, Goldsmith's model might seem to endorse a literary equivalent of arrested development, an embryonic form of writing that never makes it to the self-expressive stage, let alone to an intermediary imitative one. Conversely, we might look at Goldsmith's work as, precisely, a strategy for foreclosing this development and keeping the indexicality of textual reproduction unsullied by mimesis. Goldsmith's project is actually far more successful in halting this mimetic process than it is at stymying self-expression. Indeed, given that the indexicality of Goldsmith's model ends up foregrounding the author's subjectivity, as we saw, the variance between Goldsmith's and Cassill's literary advice is not really a question of whether they promote a self-expressive model or not (they both do), but of the different ways in which they implicate copying in a self-expressive process. This is the difference, respectively, between copying as self-expression and self-expression via copying. Yet, in the case of Cassill's model, the horizon of the self that is expressed is obvious even if it is vague: it is the self through which "the writer will discover who he really is." What kind of self would Goldsmith's model lead his readers to express? 


\section{Literary Advice for the Twenty-First Century?}

In its paradoxical tracing of the origins of originality to its putative antithesis, to copying and mimesis, Cassill's model evokes a parallel to the term "unoriginal genius." This expression is used by Marjorie Perloff, one of conceptual writing's most conspicuous champions, to refer to figures such as Goldsmith; Goldsmith himself reiterates the term in his stated ambition to teach his students to be "unoriginal geniuses" (Goldsmith 2011, p. 217). For the critic John Douglas Millar, the contradictory implications of this phrase encapsulate "a complex dialectical relation between Romanticism and Conceptualism" that also marks LeWitt's critical writings (Millar 2016, p. 41). ${ }^{8}$ As a term, "unoriginal genius" certainly speaks volumes of the way in which the author's subjectivity and persona ultimately take center stage in Goldsmith's practice. What rings particularly true is Perloff's observation that "however unoriginal its actual words and phrases," Goldsmith's appropriative work boils down to a question of "individual taste" (Perloff 2010, pp. 168-169). The "genius" of such unoriginality, to put it in the indexical terms of Goldsmith's project, would thus depend on the distinctiveness with which the deictic traces of this individual taste are realized as performative evidence. This is the crux of copying as self-expression. Needless to say, it is a model that promotes identities which, in their own way, are no less "stable and authentic" than those encouraged by the old-fashioned literary advice of Cassill's Writing Fiction.

Ashton makes a related point when she observes that Goldsmith's program actualizes a transition from textual production to textual consumption. Citing Dworkin's warning that the contemporary growth rate of poetry publications "faces a Malthusian limit," she notes that "the utility of a 'consumerist poetics' is in at least one respect - that of the market itself - the logical outcome of a literary surplus" (Ashton 2018, p. 231). One way of solving the Malthusian crisis, then, is to fall back on "the desires of the reader/consumer," "the realm of "individual choice" (ibid.). These insights give a slightly different slant to Goldsmith's proclamation that aspiring writers "must learn to negotiate the vast quantity" of texts that are already out there. In light of the above, a big part of their training as "unoriginal geniuses" would pivot less on their being the negotiators of this surplus than its keen-eyed consumers.

Kaufmann, in fact, views Goldsmith's practice in a strikingly similar way, positioning it on a spectrum that straddles his activities as founder 
and curator of UbuWeb (a well-known online archive of vanguard art and literature), his "hiply retro" fashion sense, and a persona that "elides the distinctions between the collector, the artist and the aesthete" (Kaufmann 2017, pp. 2, 18). Hence what Kaufmann describes as Goldsmith's own "transmediations" — by dint of which "[n] ewspapers, television news, radio reports become books, and more importantly, [...] art" (ibid., pp. 19-20)-are treated as an extension of a broader curatorial project. Kaufmann does not factor photography into his assessmentand, of course, given that it is a medium that Goldsmith's work is not especially concerned with, there seems no need for him to do so. Yet the indexical formulas that structure Goldsmith's curatorial impulse follow a proto-photographic logic: as Susan Sontag was at pains to highlight in her essays on photography, photographs "do not seem to be statements about the world so much as pieces of it, miniatures of reality that anyone can make or acquire" (Sontag 1977, p. 4). Here we get an inkling not only of the deprivileging of the constative that seems integral to indexical operations, but of their "transposition of an object from the continuum of reality" as a kind of performance of consumption.

We can envision how this performance might take place by revisiting Goldsmith's writing exercises. Both Cassill and Goldsmith rationalize textual reproduction as, among other things, a species of absorbed readerly engagement. "Copying obliges you to read all the words," Cassill writes (1962, p. 55), while Goldsmith recounts how a student found the "Retyping Five Pages" exercise to be "the most intense reading experience she's ever had" (Goldsmith 2011, p. 153). Yet while for Cassill this engagement lays the necessary groundwork for assimilating style, in Goldsmith's case it is not vital to the task of literary reproduction: Goldsmith explains for instance that, in order to produce Day, he used OCR software to automatically transcribe as much of the New York Times issue as possible. Even if it ostensibly prescribes faithful retyping, the "Retyping Five Pages" exercise could just as plausibly be done without really engaging with the target text-for instance, through copy-pasting or, indeed, photographing it. Executing the task could in this sense be said to imitate a process of performative consumption.

Once we consider the indexicality of Goldsmith's writing model in these terms, links start to emerge between his practice and certain patterns of performativity in the digital sphere. Jeffrey Nealon has remarked that, because it resists lyricism and "artistic hermeneutics," Goldsmith's work suggests "one strategy for dealing with the colonization of everyday life 
by the increasing saturation of affective capitalism - which no longer just wants you to produce for it from nine to five; it wants you to prosume (produce through consumption), and it wants you to do it $24 / 7$ " (Nealon 2017 , p. 78 ). Nonetheless, in their staging of performative consumption, the writing exercises offered in Uncreative Writing mimic the prosumer model that Nealon is referring to. Understood as "the use of digital network technologies, in which creation and consumption of the mediated content take place simultaneously and are performed by the same persons," this model is abundantly familiar to participants in the so-called gift economy (Zajc 2015, p. 31). While they of course also prompt the production and sharing of new content, many social media platforms provide arenas for simply showcasing already existing digital material. Such acts of reproduction not only function as performative evidence of the users' taste and personal choices; they operate according to a deictic principle that is essentially indexical. In short, these kinds of platforms exemplify the way in which, as Doane remarks, "the digital has not annihilated the logic of the photochemical, but incorporated it" (Doane 2007, p. 5). The fact that Goldsmith's output would appear to resonate with digital culture is, by the same token, less to do with his engagement with the digital sphere per se than with that sphere's assimilation of traditional indexical principles.

Stephens argues that, by virtue of its policy of passive indexing, "conceptual writing demonstrates considerable self-reflexivity with respect to the conditions of its own existence and dissemination in an era of instantaneous global information flows" (Stephens 2015, p. 154). However, Goldsmith's model does not really engage in a critique or exploration of these conditions, but expands into the realm of writing a "desire for a photographic logic [that] has only been intensified by the emergence of the digital" (Doane 2007, p. 5). Or, to frame this in the terms of Goldsmith's own analogy to painting: rather than being a writerly response to the emergence of the Internet that corresponds to modern painting's reaction to photography, his literary advice merely extends a proto-photographic logic into the territory of contemporary literature. Through this extension, Goldsmith furnishes aspiring authors with ideas for tapping into an indexical approach to writing. Even if the principle of copying it hinges on has been a longstanding ingredient of literary advice, his model therefore has an undeniable pedagogical utility. Whether it also points to the future of writing handbooks - let alone of literatureis nonetheless more debatable. By promoting reproduction as a form of 
literary production, his book offers a valuable addition to the field of literary advice that ultimately participates in, rather than counters, the contemporary quest for authentic self-expression.

Acknowledgements I would like to thank my doctoral supervisor, Pieter Vermeulen, my colleague, Tom Chadwick, and the editors of this volume for their very helpful comments on earlier drafts of this article. My thanks also go to the FWO (Research Foundation Flanders), under whose financial auspices this text was written (Project $1172720 \mathrm{~N}$ ).

\section{Notes}

1. The New York trilogy consists of The Weather (2005), Traffic (2007), and Sports (2008).

2. Krauss is here adapting C.S. Peirce's theorization of the index.

3. It should be mentioned that certain theorists have raised objections to the notion that photography is fundamentally indexical. See, for example, Joel Snyder's "Pointless" in Photography Theory (2007). While acknowledging that, as a sign, the photograph is not merely reducible to its indexicality, the current article begins from the assumption that photographs are indexical in a way that other types of cultural artifacts, such as paintings or drawings, are not.

4. Although the term "shifter" was first introduced by Otto Jespersen as early as the 1920s, it entered wider currency through Roman Jakobson's 1957 essay "Shifters, verbal categories, and the Russian verb." It is worth noting that there are parallels between Jakobson's insights and Émile Benveniste's observations on the deictic quality of personal pronouns.

5. Henri Van Lier has also highlighted what he calls the "indiciality" of the photograph's indexical quality in his Philosophy of Photography (2007).

6. The obvious exception is "Transcribing Project Runway": as Goldsmith notes, the show's transcription process (and subsequent editing of the transcript) is a group effort. It could nonetheless be argued that while the assignment aggregates (and thus dilutes) the students' individual transcription choices, the choice of source material expresses Goldsmith's recognizable taste for the banal and Warholesque. Strictly speaking, "Transcribing Project Runway" appears to be the least indexical of the tasks, producing rhythmical (and often inaccurate) repetitions of phrases scattered across the transcript.

7. For a discussion that acknowledges the diversity of current approaches to creative writing alongside that of the Iowa model, see Seth Abramson, "From Modernism to Metamodernism: Quantifying and Theorizing the Stages of the Program Era" (2016). 
8. Millar is here drawing on Peter Osborne's critique of Sol LeWitt's conceptual art principles (see Osborne 2013, pp. 37-69).

\section{REFERENCES}

Abramson, Seth. 2016. From Modernism to Metamodernism: Quantifying and Theorizing the Stages of the Program Era. After the Program Era: The Past, Present, and Future of Creative Writing in the University, ed. Loren Glass, 233-248. Iowa City: University of Iowa Press.

Anonymous. 1786. Anecdotes of Voltaire. The Edinburgh Magazine, or Literary Miscellany. Volume III, 409-412. Edinburgh: Macfarquhar and Elliot.

Ashton, Jennifer. 2018. Conceptual Writing. In American Literature in Transition: 2000-2010, ed. Rachel Greenwald Smith, 224-235. Cambridge: Cambridge University Press.

Cassill, R.V. 1962. Writing Fiction. New York: Pocket Books.

Doane, Mary Ann. 2007. Indexicality: Trace and Sign: Introduction. Differences: A Journal of Feminist Cultural Studies 18 (1): 1-6.

Dworkin, Craig. 2011. The Fate of Echo. In Against Expression, ed. Craig Dworkin and Kenneth Goldsmith, xliii-xliv. Evanston, IL: Northwestern University Press.

Goldsmith, Kenneth. 2011. Uncreative Writing: Managing Language in the Digital Age. New York: Columbia University Press.

Kaufmann, David. 2017. Reading Uncreative Writing: Conceptualism, Expression, and the Lyric. Basingstoke: Palgrave Macmillan.

Krauss, Rosalind. 1977. Notes on the Index: Seventies Art in America. October 3: $68-81$.

Kuhl, Nancy. 2005. Personal Therapeutic Writing vs. Literary Writing. In Power and Identity in the Creative Writing Classroom: The Authority Project, ed. Anna Leahy, 3-12. Clevedon: Multilingual Matters Ltd.

McGurl, Mark. 2007. Understanding Iowa: Flannery O'Connor, B.A., M.F.A. American Literary History 19 (2): 527-545.

Millar, John Douglas. 2016. Brutalist Readings: Essays on Literature. Berlin: Sternberg Press.

Nealon, Jeffrey T. 2017. Realisms Redux; or, Against Affective Capitalism. In Neoliberalism and Contemporary Literary Culture, ed. Mitchum Huehls and Rachel Greenwald Smith, 70-85. Baltimore: Johns Hopkins University Press.

Osborne, Peter. 2013. Anywhere Or Not at All: Philosophy of Contemporary Art. London: Verso.

Peary, Alexandria. 2014. Taking Self-help Books Seriously: The Informal Aesthetic Education of Writers. The Journal of Aesthetic Education 48 (2): 86-104. 
Perloff, Marjorie. 2010. Unoriginal Genius: Poetry by Other Means in the New Century. Chicago: University of Chicago Press.

Sage, Leland L. 1974. Iowa Writers and Painters: An Historical Survey. The Annals of Iowa 42 (4): 241-270.

Snyder, Joel. 2007. Pointless. Photography Theory, ed. James Elkins, 369-400. New York: Routledge.

Sontag, Susan. 1977. On Photography. New York: Farrar, Straus and Giroux.

Stephens, Paul. 2015. The Poetics of Information Overload: From Gertrude Stein to Conceptual Writing. Minneapolis: University of Minnesota Press.

Van Lier, Henri. 2007. Philosophy of Photography. Leuven: Leuven University Press.

Wandor, Michelene. 2008. The Author Is Not Dead, Merely Somewhere Else: Creative Writing Reconceived. Basingstoke: Palgrave Macmillan.

Zajc, Melita. 2015. Social Media, Prosumption and Dispositives: New Mechanisms of the Construction of Subjectivity. Journal of Consumer Culture 15 (1): $28-47$.

Open Access This chapter is licensed under the terms of the Creative Commons Attribution 4.0 International License (http://creativecommons.org/licenses/ by $/ 4.0 /$ ), which permits use, sharing, adaptation, distribution and reproduction in any medium or format, as long as you give appropriate credit to the original author(s) and the source, provide a link to the Creative Commons license and indicate if changes were made.

The images or other third party material in this chapter are included in the chapter's Creative Commons license, unless indicated otherwise in a credit line to the material. If material is not included in the chapter's Creative Commons license and your intended use is not permitted by statutory regulation or exceeds the permitted use, you will need to obtain permission directly from the copyright holder.

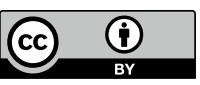

